\title{
Fronts and eddies as key structures in the habitat of marine fish larvae: opportunity, adaptive response and competitive advantage
}

\author{
ANDREW BAKUN \\ Pew Institute for Ocean Science, Rosenstiel School of Marine and Atmospheric Science, University of Miami, \\ 4600 Rickenbacker Causeway, Miami, Florida 33131, USA. E-mail: abakun@rsmas.miami.edu
}

\begin{abstract}
SUMMARY: Surface fronts and mesoscale eddies are two classes of ocean structures that engender significant pattern in the habitats of marine organisms. Both are sites where mechanical energy of the physical system may be accessible for augmenting trophic energy available to biological organisms. Accordingly, they may offer opportunities for exceptional local productivity and growth of species particularly adapted to excelling in such highly-productive rapid-growth/high-mortality situations. The major relevant physical mechanisms involved are presented. A widespread attraction of many types of fish to floating objects drifting in the ocean is cited as an apparent adaptive response to the desirable aspects of surface fronts. An apparent contrary tendency for certain important marine fish species to be particularly successful in relatively poorly productive situations, where slower growth may be offset by much lower early life predation mortality, is also noted. Competing tradeoffs between (1) early life nutrition and resulting growth, and (2) mortality of early stages due to predation are suggested. These tradeoffs are posed and illustrated via a "predator pit" conceptual framework. Illustrations of the evident reproductive habitat choices of several populations of large temperate tunas are briefly presented. It is concluded that the time may have come for a general shift in the approach of at-sea fish larval ecological investigations from the conventional focus on associations with environmental properties on a "macro" scale to intensive investigations of the real-time progressions of linked physical-biological interactions occurring on a "meso" (and smaller) scale.
\end{abstract}

Keywords: population dynamics, fisheries oceanography, convergence zones, divergence zones, upwelling, predator pits, ecological succession, tuna spawning areas.

RESUMEN: FRENTES Y REMOLINOS COMO ESTRUCTURAS CLAVE EN EL HABITAT DE LAS LARVAS DE PECES MARINOS: OPORTUNIDAD, RESPUESTA ADAPTATIVA Y VENTAJA COMPETITIVA. - Los frentes superficiales y los remolinos de mesoescala son dos tipos de estructuras de mesoescala que producen patrones significativos en los hábitats de los organismos marinos. Ambos son notables por ser lugares en los que la energía mecánica del sistema físico puede ser accesible para aumentar la energía trófica disponible para los organismos biológicos. Por consiguiente, pueden ofrecer oportunidades para que se produzcan producciones y crecimientos localmente excepcionales de especies particularmente adaptadas a sobresalir en tales situaciones de alta producción/rápido crecimiento/alta mortalidad. Los mecanismos físicos de mayor relevancia involucrados son elaborados. La amplia atracción de muchos tipos de peces por objetos flotantes que derivan en el océano ha sido señalada como una aparente respuesta adaptativa a los aspectos deseables de los frentes superficiales. Existe una tendencia aparentemente contraria para ciertas importantes especies de peces marinas que son particularmente exitosas en situaciones productivas relativamente pobres, en las que se ha señalado que un crecimiento más lento podría ser contrarrestado por una menor mortalidad por predación en los primeros estadios de desarrollo, sugiriendo competencias compensadores entre (1) la nutrición y crecimiento resultante en las primeras fases de desarrollo, y (2) la mortalidad debida a la predación en estos primeros estadios. Estas contraposiciones se plantean y se ilustran vía un marco conceptual, el "hoyo de predación". Se presentan brevemente ilustraciones de las "opciones" del hábitat reproductivo escogidas por varias poblaciones de grandes atunes de zonas templadas. Se extrae la conclusión de que puede haber llegado el momento de un cambio general en la "moda" de las investigaciones ecológicas sobre larvas de peces en-mar, enfocadas convencionalmente en asociaciones con las características ambientales a macroescala, hacia investigaciones intensivas de las progresiones en tiempo real de las interacciones físicobiológicas que suceden a mesoescala (y a menores escalas).

Palabras clave: dinámica de poblaciones, oceanografía pesquera, zonas de convergencia, zonas de divergencia, afloramiento, "hoyo de predación", sucesión ecológica, áreas de freza del atún. 


\section{INTRODUCTION}

Conventional fisheries management techniques have not been sufficient to prevent a growing number of collapses of important marine resource populations. There are undoubtedly several reasons for this. One of these is certainly the limited current ability to assemble a comprehensive system of truly ecosystem-based fishery management (EBFM) (Pikitch et al., 2004). Probably another is the current practice of relying on large-scale averages of critical rates and abundance levels in predicting or simulating potential results of alternative fishing practices or management actions. The assumption that calculations based on mean rates and quantities should yield realistic predicted or simulated mean "outcomes" appears to be a tenuous one at best. Underlying such potentially flawed intuitions is the fact that we humans are terrestrial organisms, so our accumulated store of intuitions and experiences is nearly entirely terrestrially-based.

For example, in the terrestrial situation, the most important dynamic constraint is gravity. Every active movement of a terrestrial organism (other than falling) must have an element that acts to oppose the incessant pull of gravity. On the other hand, in the ocean, where most organisms are nearly neutrally buoyant, the law of gravity becomes relatively inoperative, and the laws of hydrodynamics take its place. Frictional drag replaces the pull of gravity as the major constraint to active movement. In a liquid environment, size offers distinct advantages; larger fish can generally swim faster, while using relatively less energy, than smaller fish. Thus, a predator can usually catch any smaller prey it locates, provided it is willing to expend the required energy. Furthermore, the pelagic environment offers scant cover or safe refuge. The salvation of a pelagic prey population often seems to lie merely in the sheer mass of water that must be searched or filtered by its predators. The energy expended by a predator in encountering and gathering prey (plus that expended for physiological maintenance, growth, and reproduction) must be matched by the caloric content of the ingested food or it must soon either switch its choice of prey, migrate to a location of greater prey density, enter an energy-conserving inactive state to await better feeding conditions, or starve. A predator population can increase its size only up to the point at which a situation of continued energy deficit is encountered by its members at some point in their life cycle. The result may be that, on a large-scale average basis, much of the ocean may be locked in a "minimal net gain" situation, where the productivity of each trophic level is driven to a very low level by unrelenting over-exploitation exerted by the next higher trophic level (in direct analogy to a situation of over-exploitation of a resource population by an unmanaged over-capitalised fishery).

In any case, wherever one looks in the ocean, one is impressed by a striking coincidence of high levels of biological activity with various types of interfaces (Legendre and Demers, 1984) created by physical ocean processes and constraints (Bakun, 1996). Such interfaces represent sites where the energy of the physical system becomes in some way available to augment the trophic energy of the biological system. At these locations, each successive trophic level may be released from the "minimal net gain" situation that may characterize the large-scale average for the habitat. This may produce local blooming in individual growth, in reproductive output, and eventually in local population growth at each trophic level, ultimately attracting larger nektonic predators to the locally enriched trophic pyramid (Bakun, 1996). Prime examples of such advantageous interface structures are the ocean fronts that are formed at the interfaces between differing water types (i.e. ones having differing characteristic temperatures or salinities). Likewise, in cases where distributions of larval fishes have been adequately resolved, a striking correspondence to mesoscale eddy features is commonly observed.

\section{OCEAN FRONTS}

Surface fronts, delineating boundaries between different surface water types, are ubiquitous in the ocean. Their importance to ecosystem processes lies in the fact that any distinct front that persists over a significant time frame must be associated with a convergence zone. Otherwise, lateral turbulence, which always exists to some degree in the ocean and particularly in the energetic surface zone, would act to progressively blur and erase the frontal structure. Indeed, the dynamic forces involved when two water masses of different densities come into proximity act to ensure that convergence occurs at their zone of intersection. Mixing processes near the interface produce water of intermediate density that 


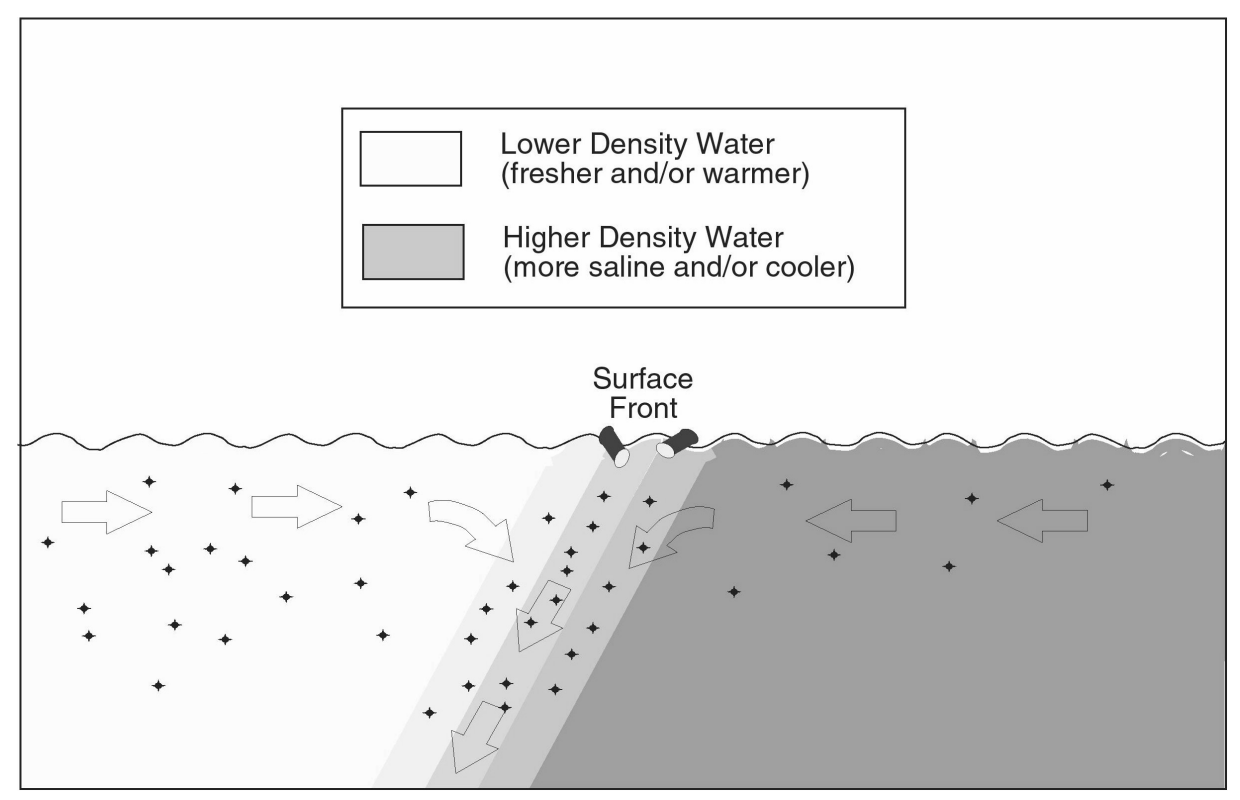

FIG. 1. - Schematic diagram of a front between waters of differing density. Arrow-shaped symbols indicate density-driven flows associated with the front. "Particle" symbols signify planktonic organisms capable of resisting being carried downward in the sinking water motion. (Scales are distorted: vertical scale greatly expanded relative to horizontal; particles greatly magnified; surface waves not to scale, etc.) After Bakun (1996).

tends to flow under the less dense surface water type. Thus, both surface water types are feeding the formation of a mass of mixed water that slowly sinks at the interface between them. Even in cases in which the two water types may have equal densities, the mixture of the two will tend to have a greater density through a process known as cabbeling (You, 2003; Yun and Talley, 2003). The buoyancy-driven flows that supply this mixed water formation are directed from each of the water types toward the interface, resulting in a zone of convergence that acts to maintain the distinct frontal character of the boundary (Fig. 1).

Minute weakly-swimming organisms that may be unable to resist being passively swept along within the horizontal ocean flow field may well be able to control their depth level in the much less energetic field of vertical motion in the ocean. Such organisms will thus accumulate in the slowly sinking waters of the convergent frontal zone (Fig. 1). Here, the distribution of food particles tend to be concentrated and feeding organisms may realize dramatically increased caloric intake per unit energy expenditure compared to the much more extensive areas of ocean that lack such a physically-driven concentration mechanism. Characteristically, this leads to the multi-trophic-level blooming of productivity described in the previous section.

The importance of processes occurring in or near ocean fronts appears to be exemplified by the evident attraction of a wide variety of fish and other marine animals to floating objects. The actual convergent water motions associated with a front may be too subtle to be directly sensed by pelagic organisms operating in an environment devoid of fixed reference points, particularly since the geostrophic current parallel to the front (that is in equilibrium with the cross-front pressure gradient linked to the density contrast between the water masses on either side of the front) would tend to be much stronger than the non-geostrophic densitydriven flows perpendicular to the front that produce the convergent situation depicted in Figure 1. Moreover, the distributions of biological distributions (i.e. potential prey organisms) tend to be so patchy in the ocean that a fish seeking an advantageous location to search for potential prey may find little available indication of relative favourability. However, drifting objects floating on the ocean surface tend to be carried into and to accumulate within convergent frontal structures (as suggested in Fig. 1). An innate attraction to drifting objects (i.e. an instinctive level of comfort in their vicinity that has been instilled over multitudinous generations by Darwinian selection) would serve to automatically position the fish within such convergent zones where enhanced biological activity may lead to improved probability of encountering favourable feeding opportunities. The use of fish aggregating devices or FADS, floating rafts of logs 
or other materials that are either allowed to drift freely or anchored in convenient locations in order to attract and concentrate fish, thereby enhancing fishing success, is one way in which modern fisheries exploit this behaviour pattern.

\section{MESOSCALE EDDIES}

The ocean is a turbulent fluid, and turbulent eddy motions are ubiquitous in marine ecosystems (Olson, 1980, 1991; Glorioso et al., 2005). One is easily convinced of the biological relevance of eddy motions when looking at satellite images of ocean surface colour. The nature of the patches and swirls of the chlorophyll pigments, which are of course the basic element in the production of the trophic energy that must ultimately sustain nearly all life in the ocean, are obviously related to, and apparently determined by, the eddy structure of the underlying fluid flow. Eddies nearly always (1) contain embedded frontal interfaces (here we speak of baroclinic eddies; the other type, barotropic eddies, are neither easily detectable nor do they produce the biological effects addressed here), and (2) like fronts, embody mechanisms by which the physical energy of the ocean system can be converted to trophic energy to support biological processes. The fact that cyclonic mesoscale eddies can drive upwelling in their interiors is quite well known among marine biological scientists. Somewhat less well known is the fact that both cyclonic and anti-cyclonic eddies may embody either upwelling or downwelling in their centres, depending on whether they are forced eddies (i.e. "spinning up" under direct frictional forcing) or free eddies (where either the forcing has been interrupted or the eddy has drifted away from the originating forcing source so that the eddy is now decaying or "spinning down"). (Terminological note: rotation in the same sense as the earth's rotation, i.e. anti-clockwise in the northern hemisphere and clockwise in the southern hemisphere, is assigned the term "cyclonic"; rotation in the opposite sense in either hemisphere is termed "anticylonic".)

Associated with the vertical motions in the interior of the eddies are patterns of divergence and convergence in the horizontal flow field, which can concentrate or dilute distributions of planktonic organisms that have the capacity to exert some degree of control over their depth levels. A forced anticyclonic eddy will feature a predominately convergent flow pattern in the surface layer of the interior of the eddy, with attendant biological implications somewhat similar to those described above for ocean surface fronts. This convergent flow pattern will in addition tend to favour development of convergent frontal structures (that often appear to spiral around the eddy interior). In contrast, a forced cyclonic eddy will tend to have a divergent surface flow pattern that will act to thin out distributions of planktonic organisms. Consequently, initial expectations that the nutrient inputs due to the upwelling that occurs in forced cyclonic eddies should be reflected in chlorophyll hotspots in satellite ocean colour images are often not met. There may be plant nutrients in abundance, but there may also be quite low phytoplankton concentrations due to the diluting effect of the divergent surface flow field and the corresponding input of waters newly upwelled from depth where light levels had been low and where therefore organisms dependent on photosynthesis to meet their trophic needs may necessarily have existed only in very low abundance.

In the types of eddies where upwelling and divergence typify the interiors, convergence and downwelling often occur near the edges. Likewise, convergent eddy interiors may often be surrounded by zones of upwelling and divergence situated near, and just beyond, the eddy's outer edges. Thus, eddy motions in the ocean yield a rich landscape of ocean triad configurations (Bakun, 1996) where mechanisms of enrichment, concentration and retention may be arranged in particularly favourable sequences to produce outbursts in biological productivity and reproductive success of organisms capable of using them to advantage.

Indeed, it is possible that when a forced anticylonic eddy is small enough, rotating rapidly enough, and/or near enough to the earth's equator, it may actually be divergent in its interior rather than convergent. But then, if it drifts away from the location of its formation, its rotation slows due to the action of the intense opposite frictional torques acting on such a relatively small, rapidly spinning parcel of water and it abruptly transforms to a convergent state. In such a case, initial enrichment is directly followed by convergence and concentration of the products of that enrichment, which are retained within the eddy (the classic ocean triad sequence) along with any fish larvae, etc., that may have been spawned within the eddy by opportunistically-feeding nektonic adults. 
So all of this ("cyclonic" or "anticyclonic", "interiors" or "edges", "small enough", "rotating rapidly enough", "near enough to the equator", etc.) may sound quite complicated. But actually, if one understands just a little about the mechanics involved, it can all become quite logical and fairly simple. (Interested readers are encouraged to read through the following section, even if the mathematical formulae might appear somewhat daunting. They are placed here for the convenient reference of readers who are equipped to use them. However, one does not have to necessarily understand the mathematical operations expressed in the formulae to follow the logic of the verbal argument.)

\section{A BRIEF PRIMER ON EDDY DYNAMICS}

In order to remain an identifiable integral entity (i.e. to neither fly apart nor collapse into itself), an eddy must represent an approximate balance among the dynamic forces involved in its motion. Neglecting frictional forces for the moment, the forces involved are horizontal pressure forces due mainly to spatial variations in sea surface topography, Coriolis force due to the earth's rotation, and centrifugal force due to the curvature of the flow

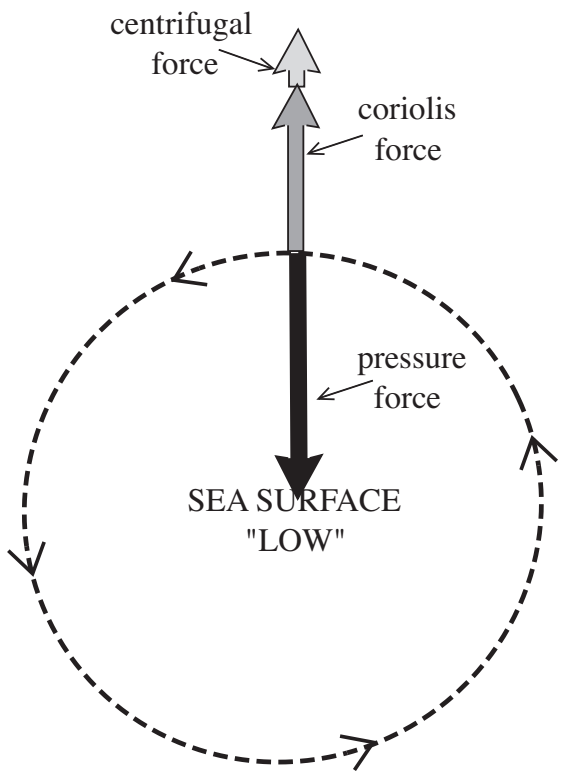

a. CYCLONIC EDDY pattern. In a cyclonic eddy the Coriolis and centrifugal forces are directed radially outward, with a balancing pressure force directed inward toward a local "low" in the sea surface topography located at the eddy core (Fig. 2a). In an anticylonic eddy, the Coriolis force is directed inward toward the eddy's centre, while the centrifugal force is directed outward. In most anticyclonic mesoscale eddies (i.e. except in a particular special case discussed in a later section of this paper) the Coriolis force is larger than the centrifugal force, so the dynamic balance is maintained by a pressure force directed radially outward from a local "high" situated at the eddy's centre (Fig. 2b).

It is the action of frictional forces in perturbing the balance among these three dominant forces that drives the evolution of the eddy features, as well as such biologically-pertinent aspects as horizontal convergence or divergence, and resulting upwelling or downwelling. These aspects can be explored most simply from the point of view of vorticity, which is a measure of the rotational character of the horizontal flow pattern that represents the combined rotational effects of both curvature and shear in the horizontal velocity field (see any textbook offering an elementary treatment of vector calculus, e.g. Spiegle, 1959).

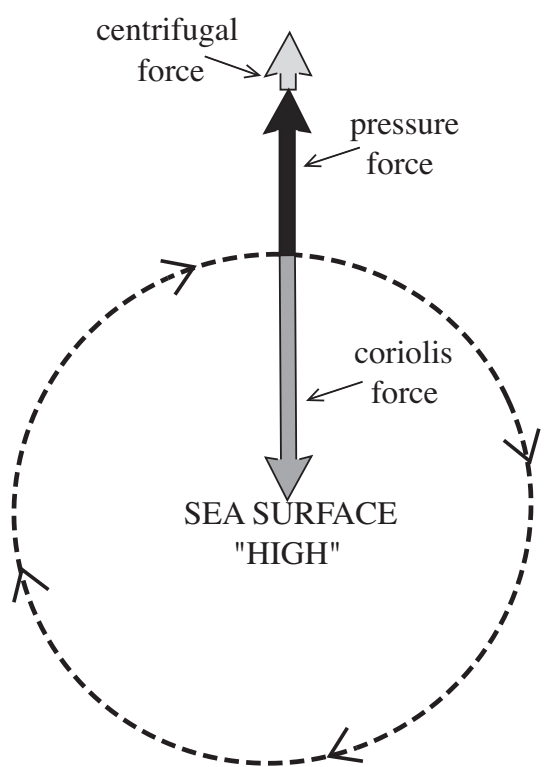

b. ANTICYCLONIC EDDY

FIG. 2. - The major force balances existing in (a) a cyclonic eddy, and (b) an anticyclonic eddy. Differences in lengths of the thick arrow symbols are intended to imply relative magnitudes of the forces represented. Dotted "L" or "H" labels indicate a local "low" or "high", respectively, in the sea surface topography. (Northern hemisphere versions are shown; versions appropriate for the southern hemisphere would be identical in all respects, excepting only that the directions of rotation of each of the diagrammed eddies would be reversed.) 


\section{The vorticity equation}

Consider an idealised 2-layer ocean having an upper surface layer of depth $\delta$. If the two component Navier-Stokes equations (the fundamental dynamic equations governing fluid flows on the rotating earth) for the two orthogonal components of flow integrated over the upper layer are cross-differentiated and subtracted one from the other, the pressure disappears as an explicit variable, but rather is treated implicitly (i.e. does not appear). The following equation results (Hess, 1959):

$$
\begin{array}{ccc}
\begin{array}{c}
\text { term 1. rate } \\
\text { of change of } \\
\text { vorticity }
\end{array} & \begin{array}{c}
\text { term 2. rate of } \\
\text { upwelling through } \\
\text { the layer bottom }
\end{array} & \begin{array}{c}
\text { term 3. frictionat } \\
\text { torques }
\end{array} \\
\int_{-\delta}^{0} \frac{d(\zeta+f)}{d t} d z+(\zeta+f) w_{\delta}=\int_{-\delta}^{0} \operatorname{curl}_{H} \vec{F} d z
\end{array}
$$

Here $x, y$ and $z$ represent the respective eastward, northward and upward spatial coordinates, $\zeta$ signifies the horizontal vorticity (or equivalently the horizontal curl) of the velocity field ( $\zeta \equiv \operatorname{curl}_{\mathrm{H}} \vec{v} \equiv \partial v / \partial x$ - $\partial u / \partial y$, where $u$ and $v$ are the horizontal velocity components of the velocity vector, $\vec{v}$, that are directed toward the respective positive $x$ and $y$ coordinate directions), $f$ is the Coriolis parameter, $w_{\delta}$ is the vertical flow velocity (positive upward) through the bottom of the ocean's upper relatively-homogeneous layer (the thickness of which, $\delta$, is assumed to adequately approximate both the Ekman depth and the depth of the upper nearly-mixed layer), and $\vec{F}$ is the net frictional force (per unit mass) acting to accelerate ("spin up") or decelerate ("spin down") the eddy circulation $\left(\operatorname{curl}_{\mathrm{H}} \vec{F} \equiv \partial F_{y} / \partial x-\partial F_{x} / \partial y\right)$. Terms ' 1 ' and ' 3 ' will have positive values when they reflect the cyclonic, and negative values when they reflect the anticyclonic, rotational sense in either the northern or southern hemisphere. Equation 1 states that when the net frictional torques (term 3) are cyclonic (positive), the vorticity integrated through the upper layer (term 1) becomes increasingly cyclonic (or less anticyclonic), and upward motion (upwelling) through the bottom of the layer takes place (so long as the sum $\zeta+f$ is positive, as it nearly always tends to be; see the discussion in the later section of this paper on the special case of divergent forced anticyclonic eddies). Conversely, when the applied frictional torques are anticyclonic (negative), the circulation in the eddy grows more anticyclonic, and downwelling occurs in the interior of the eddy.

\section{Dynamics of forced eddies}

The mechanics involved in Equation 1 can be simply illustrated. If the net applied torques acting on a cyclonic eddy (Fig. 2a) are cyclonic (i.e term 3 of Eq. 1 is positive), they will tend to accelerate the eddy circulation (term 1), in which case both the Coriolis force and the centrifugal force increase (the eddy will be "spinning up"). This increase in outward-directed forces disrupts the balance with the now inadequate inward-directed pressure force. Consequently, water flow is forced radially outward in the upper layers within the eddy. This outward radial flow continues until loss of water and resultant lowering of the sea surface in the eddy interior reestablishes a sufficient pressure gradient (i.e. a lowering of the hydrostatic pressure near the core of the eddy) to restore a balance in the horizontal forces. The lowered hydrostatic pressure inside the eddy relative to that outside the eddy causes water in the lower layers to flow toward the eddy centre, setting up a vertical circulation that connects the convergent flow in the lower layer to the divergent flow in the upper layer (Fig. 3a).

Conversely, if the net frictional torques acting on an anticyclonic eddy are anticyclonic, the eddy circulation speeds up, increasing the Coriolis force, which then becomes larger than the sum of the pressure and centrifugal forces. This excess inwarddirected force drives water toward the interior of the eddy, augmenting the local "high" in the sea surface topography. This increases the hydrostatic pressure in the deeper layer below the centre of the eddy, causing a radial outward-directed flow in that layer, opposite to the inward-directed flow pattern in the upper layer. Downward pumping of water through the bottom of the upper layer results, connecting the flow patterns in the two layers in a continuous threedimensional flow configuration (Fig. 3b).

\section{Lateral frictional torques}

One can divide term 3 of Equation 1 into separate horizontal and vertical terms (Bakun, 1996):

$$
\begin{array}{ccc}
\begin{array}{c}
\text { term } 3 \\
\text { frictional } \\
\text { torques }
\end{array} & \begin{array}{c}
\text { term } 3 \mathrm{a} \\
\text { lateral frictional } \\
\text { torques }
\end{array} & \begin{array}{c}
\text { term } 3 \mathrm{~b} \\
\text { vertical frictional } \\
\text { torques }
\end{array} \\
\int_{-\delta}^{0} \operatorname{curl}_{H} \vec{F} d z=\int_{-\delta}^{0} A_{H}\left(\frac{\partial^{2} \zeta}{\partial x^{2}}+\frac{\partial^{2} \zeta}{\partial y^{2}}\right) d z+\frac{1}{\rho} \operatorname{curl}\left(\vec{\tau}_{s}-\vec{\tau}_{\delta}\right)(2)
\end{array}
$$




\section{a. Cyclonic - "spinning up"}

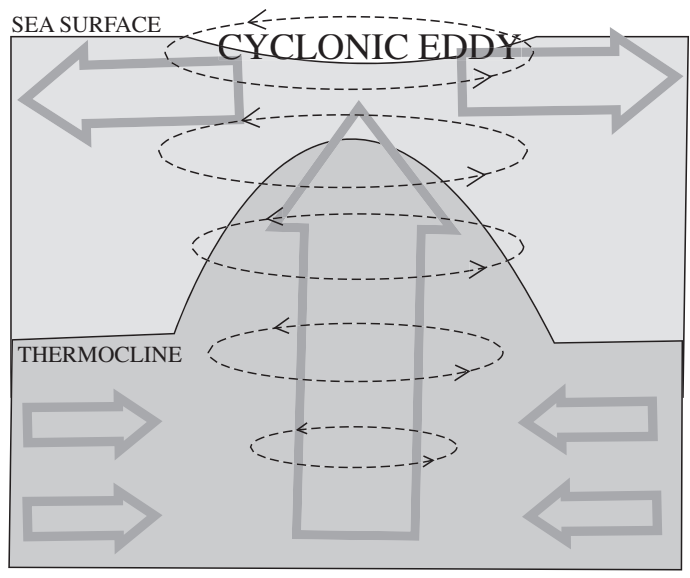

\section{c. Cyclonic - "spinning down"}

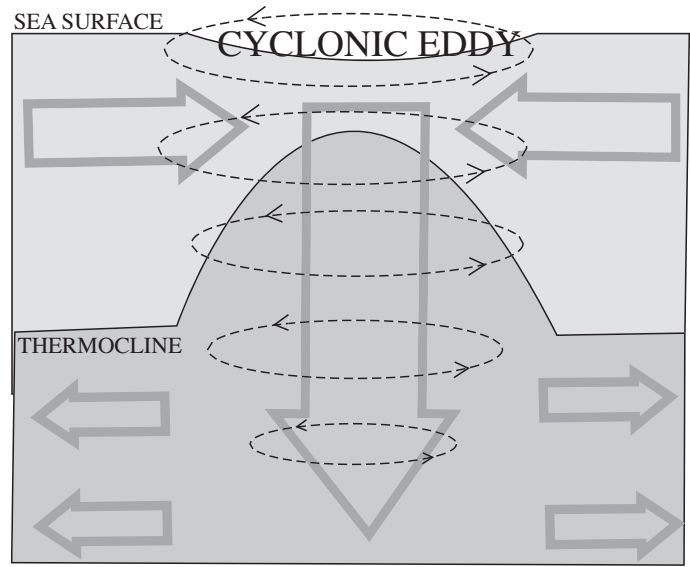

\section{b. Anticylonic - "spinning up"}

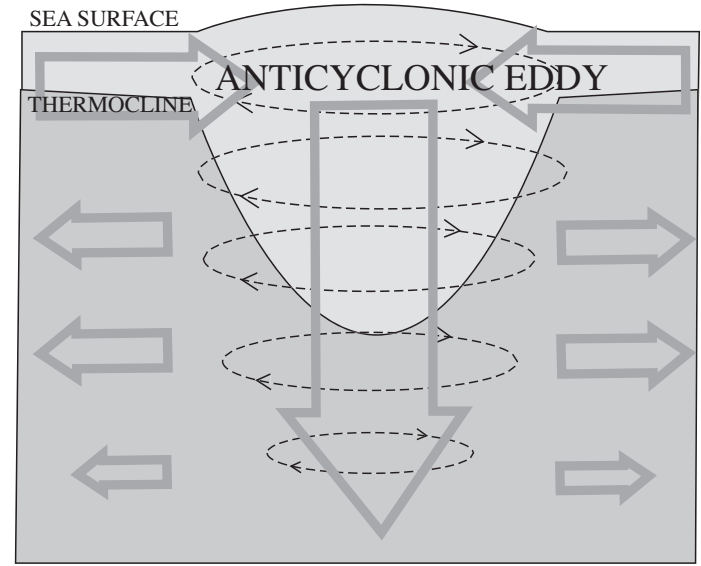

\section{d. Anticyclonic - "spinning down"}

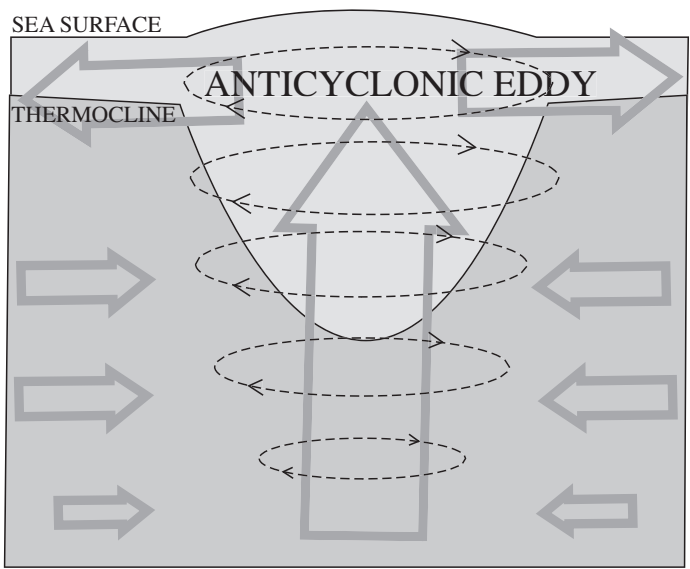

FIG. 3. - Vertical circulation patterns in (a) a forced cyclonic eddy, (b) a forced anticyclonic eddy, (c) a decaying free cyclonic eddy, (d) a decaying free anticyclonic eddy.

Here $A_{H}$ is a horizontal coefficient of turbulent friction, $\rho$ is a characteristic water density, $\vec{\tau}_{s}$ is the frictional stress exerted by the wind on the sea surface, and $\vec{\tau}_{\delta}$ is the frictional stress exerted by the upper layer, due to its relative movement, on the deeper ocean layer that lies beneath it. (When Eq. 2 is inserted into Eq. 1, i.e. terms $3 \mathrm{a}$ and $3 \mathrm{~b}$ replace term 3, and term 1 of Eq. 1 is divided into "local change" and "advective" terms, Eq. 1 becomes identical to Bakun's (1996) Appendix Eq. 10).

Term 3a expresses the effect of lateral friction that would, for example, exist in a turbulent sheer zone located on either side of the filament of maximum velocity in a strong current. In the northern hemisphere, the cyclonic side of the current is on the left, facing downstream, and the anticyclonic side is on the right. In the southern hemisphere the situation is opposite, with the cyclonic side on the right, and the anticyclonic side on the left of the maximum current flow (Fig. 4). Thus, the cyclonic side is the coastward side of (1) poleward subtropical western boundary currents such as the Gulf Stream, the Kuroshio, the Brazil Current, and the Agulhas Current, and (2) equatorward eastern ocean boundary flows such as the Canary, California Current, Benguela, and "Peru-Chile" Currents. The equatorial undercurrents (the Cromwell Current in the Pacific and the Equatorial Undercurrent in the Atlantic), being eastward-directed currents centred directly on the equator, contain predominantly 


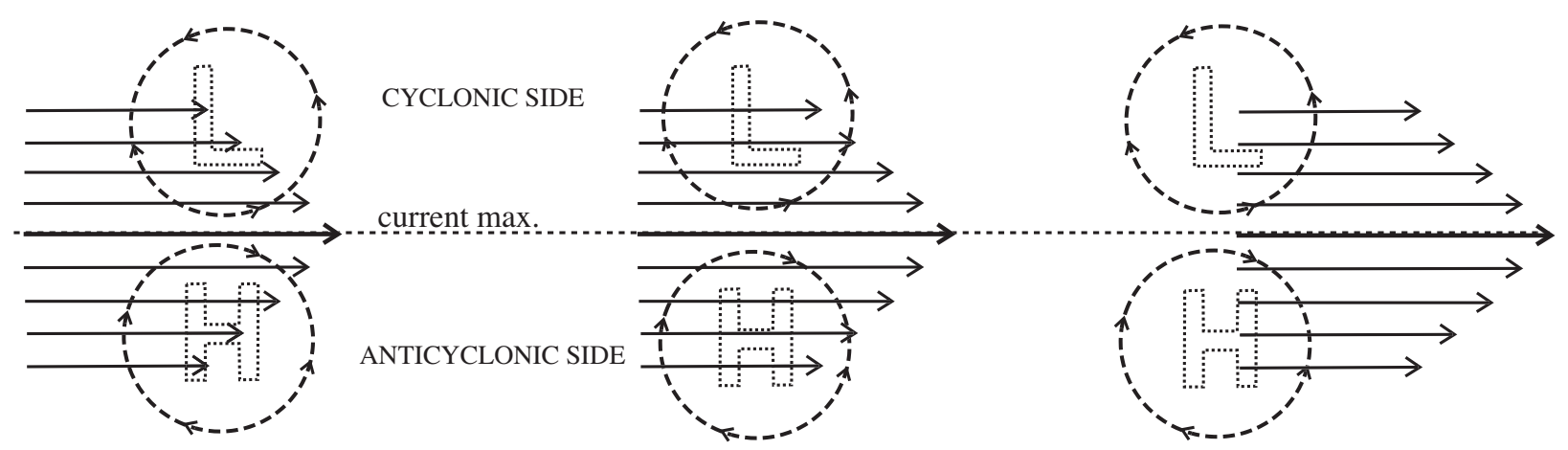

Northern Hemisphere

Southern Hemisphere

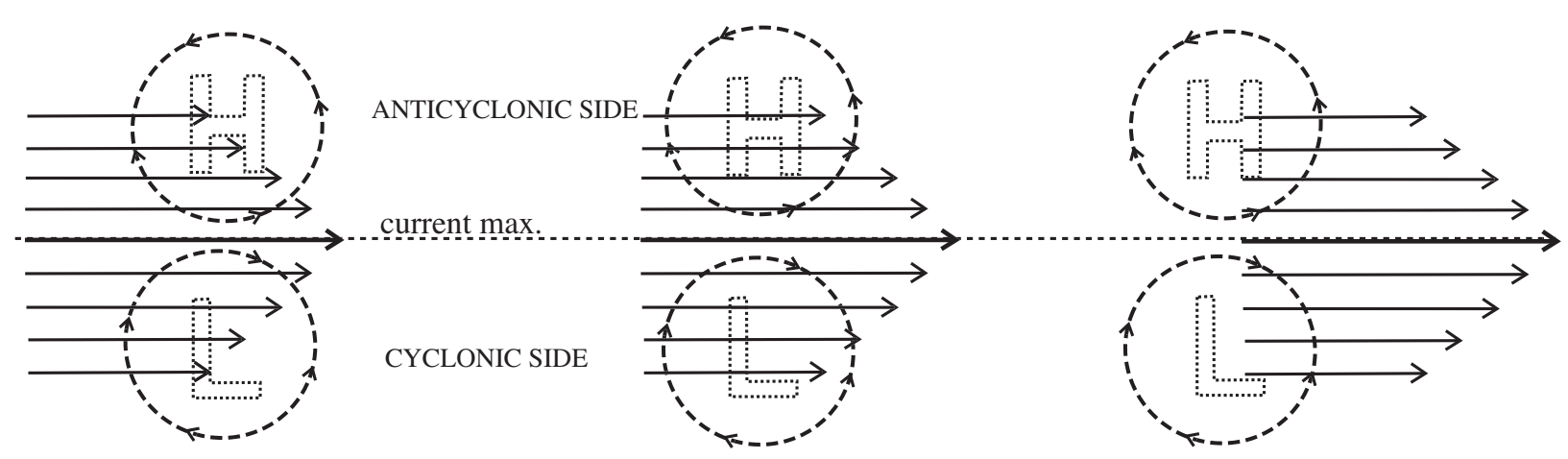

FIG. 4. - Shear zones, and associated eddy rotational tendencies arising from lateral frictional torques, existing on either side of a strong current maximum.

cyclonic sheer zones on both sides of the flow maximum. Shear zones will exert frictional torques on eddy motions within them in the same rotational sense, so cyclonic eddies will tend to be "spun up" on the cyclonic sides of flow maxima, while anticyclonic eddies will tend to be "spun up" on the anticyclonic sides of flow maxima (Fig. 4).

Note that by the same rules expressed in the previous paragraph, there will be an anticyclonic shear zone on the outer side of the strongest flow filament around a cyclonic eddy (Fig. 5a) and a cyclonic shear zone on the outer side of the maximum flow around an anticyclonic eddy (Fig. 5b). Thus, the lateral frictional effects produced by the eddies themselves will tend to spawn eddies of opposite rotational sense interspersed among them, and on either side of a strong current maximum there will be a tendency to develop a train of interspersed divergent (upwelling) and convergent (downwelling) frontal eddies.

In the lee of major capes that protrude outward into major along-coast flows, the shears between the relatively swift, uninterrupted flow and the more stagnant waters sheltered next to the coast behind the cape tend to be particularly strong. In these cases, there is a tendency for major permanent eddies to form. These often constitute important reproductive habitats for coastal pelagic fish populations (Bakun, 1996). Prominent examples include the Southern California Eddy, which encompasses the most important reproductive grounds for the small pelagic fish stocks of the California Current (Parrish et al., 1983), and the cyclonic circulation pattern in the southeastern Brazilian Bight, which is the primary reproductive habitat of the Brazilian sardine (Sardinella brasiliensis), as well as an important segment of the extended population of anchovy (Engraulis anchoita) that exists along the subtropical eastern coast of South America (Matsuura et al., 1985; Ciechomski and Sánchez, 1986).

\section{Vertical frictional torques}

Term $3 \mathrm{~b}$ of Equation 2 represents the integrated vertical frictional effect on the upper layer. It is merely the net difference between the torques 


\section{a. cyclonic eddy}

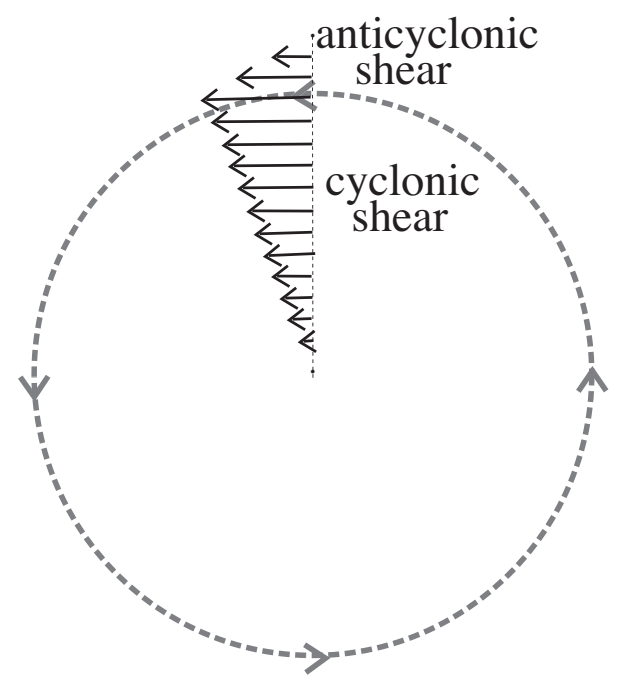

NORTHERN HEMISPHERE

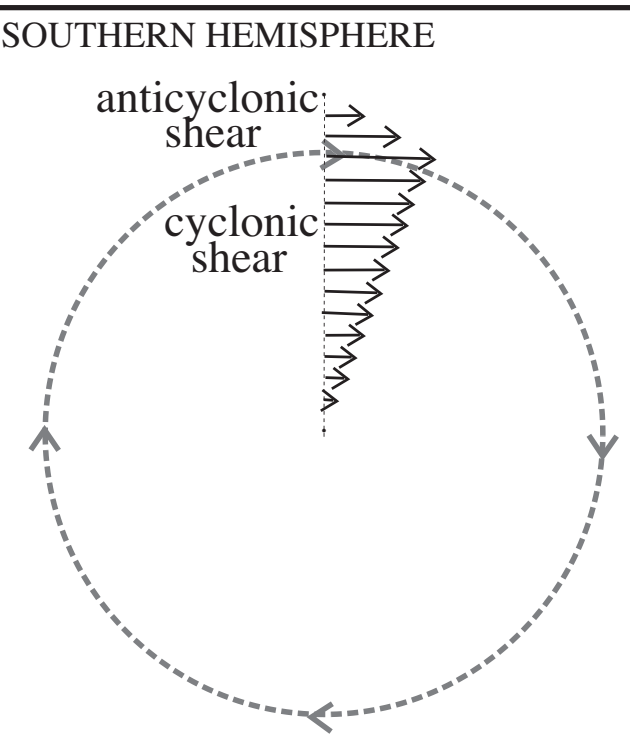

\section{b. anticyclonic eddy}

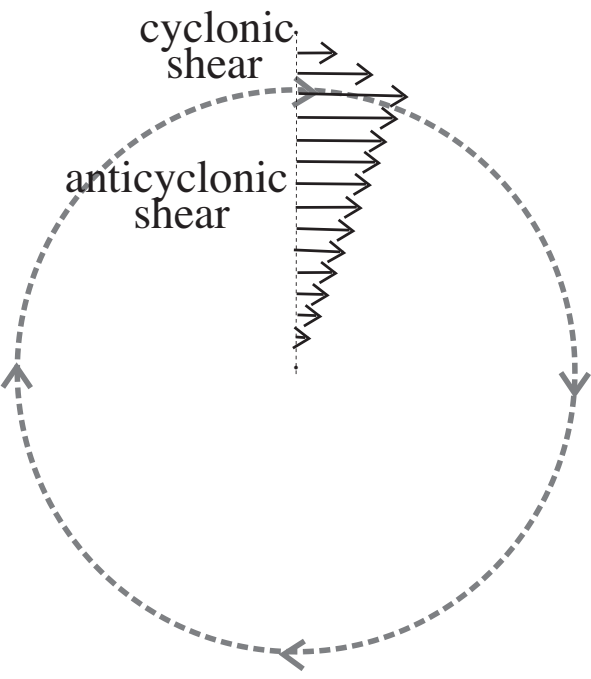

FIG. 5. - Velocity shear patterns within and just beyond the circulation maximum (i.e. the band of maximum tangential velocity) in an oceanic eddy.

applied by the curl of the wind stress acting on the sea surface and the vertical frictional torque applied by the vorticity of the flow in the upper layer on the layer beneath. Except in very strong shear flows (e.g. western boundary currents), curl $\vec{\tau}_{\delta}$ is almost always very small relative to $\operatorname{curl} \vec{\tau}_{S}$, so the curl of the sea surface wind stress provides a useful indicator of the magnitude of wind-induced open ocean upwelling (Smith, 1968; Bakun and Nelson, 1991). If the sea surface stress value is set to zero at the coastal boundary, as done by Bakun and Agostini (2001), computations of the curl of the wind stress also estimate the contribution of wind-induced coastal upwelling averaged over the spatial scale of the curl calculation.

In terms of spinning up mesoscale eddies in the open ocean, however, wind stress is not likely to be very effective. Away from coastal boundaries, the scale of horizontal variation of a wind pattern steady enough to be significant in spinning up a durable eddy will tend to be much larger than the characteristic dimensions of such an eddy. Thus, in the open ocean, direct spin-up of mesoscale eddies by the wind is probably unimportant compared to lateral friction- 
al effects exerted by current flow patterns. However, adjacent to coastal boundaries, particularly where there may be high coastal topographic relief blocking the smooth extension of the sea surface wind pattern over the coastal landmass, zones of strong lateral shear may develop. This effect is particularly striking in the areas downwind of major capes. For example, in addition to the cyclonic lateral frictional stress exerted by the California Current flow, which skirts across the seaward opening of the Southern California Bight, the Southern California Eddy may receive comparable forcing from the strong cyclonic wind stress curl pattern that is produced in the lee of Point Conception, which forms the upwind corner of the Bight (Bakun and Nelson, 1991).

\section{Free eddies}

Fairly frequently, an eddy that is not trapped in place by topography or coastal configuration may drift away from its location of origin, so the forcing that produced the eddy may essentially vanish. The eddy then becomes a free eddy, in which the primary torques are those exerted by the eddy itself, vertically on the deeper waters below it and laterally on the more quiescent waters (or at least waters of differing flow characteristics) that surround it. In this case, the torques exerted on the eddy itself are mirror images to those that the eddy exerts on its surroundings, i.e. acting in the opposite rotational sense. Thus, the right side of Equation 1 has the opposite sign to that of the vorticity value, $\zeta$, in the terms on the left side. Consequently, $w_{\delta}$ must be of opposite sign to $\zeta$ in order for the signs of the left and right sides of Equation 1 to match. Accordingly, in a cyclonic free eddy, the vertical flow that occurs in the eddy interior is mainly downward (Fig. 3c), whereas in an anticyclonic free eddy the vertical flow that occurs in the eddy interior is mainly upward (Fig. 3d). The result is four different combinations of divergence/upwelling or convergence/ downwelling in mesoscale eddies (Fig. 3), depending on the rotational sense (cyclonic or anticyclonic) and on whether the eddy in question is in a forced or free phase.

\section{Opposite vertical flow existing near the outer edge of a forced eddy}

The rules expressed on pages 111 and 112 and illustrated in Figure 5 indicate an anticyclonic shear zone on the outer side of a cyclonic eddy and a cyclonic shear zone on the outer side of an anticyclonic eddy. Thus, the torques in those particular zones will be of the opposite rotational sense to that of the eddy. According to Equation 1, this will drive an oppositely-directed vertical flow to that characterising the eddy proper. Thus, forced cyclonic eddies will tend to feature upwelling within the eddy coupled with zones of downwelling near the outer edges, linking a divergent, radially outward-directed flow pattern in the surface layer of the eddy interior with a convergent, inward-directed flow pattern at depth. Forced anticyclonic eddies will tend to exhibit the opposite situation: downwelling in the eddy interior and zones of upwelling near its edges, linking convergent, inward-directed flow in the surface layer of the eddy with divergent, radially outwarddirected flow in the deeper layer.

The actual physics involved in these dynamics, which tend to be somewhat obscured when they are addressed from the point of view of vorticity, are that the geostrophic flow around the eddy's outer edge is being retarded by lateral turbulent friction against the comparatively quiescent waters surrounding the eddy. In the case of an anticyclonic eddy, the Coriolis force thereby diminishes in that outer edge zone. The unbalanced opposing pressure and centrifugal forces push water radially outward (i.e. no longer being held in place by a balancing Coriolis force, the water actually spills down the sea surface slope from the local topographic "high" in the eddy's centre), producing convergence of less dense surface water from within the eddy with the more dense surface water of the surrounding ocean. The resulting mixed water mass, being of somewhat greater density than surface waters within the eddy, sinks beneath the convergence zone as depicted in Figure 1.

In the case of a cyclonic eddy, the outwardly directed centrifugal forces and the Coriolis forces are diminished near the eddy edge due to frictional retardation of the circumferential flow, unbalancing the pressure force that is in this case directed downslope toward the eddy centre. The unbalanced pressure force can then push water from the outward part toward the inward part of the frictionally-affected edge zone, with the result that this becomes a zone of flow convergence. An interesting example of this latter case is provided by Seki et al. (2002), who reported that catches of marlin, while clearly associated with the cyclonic eddy that characteristically 
forms in the lee of the Big Island of Hawaii (Seki et al., 2001), were found actually to be concentrated near the inshore edge of the eddy closest to the island coast. This would be the sector of most intense surface convergence in that particular configuration in which the opposite seaward outer edge of the eddy continues to be spun-up by the strong surface-level trade wind flow through the channel between the Big Island and the Island of Maui (in contrast to the retardation occurring at the edge nearest the Big Island's high-relief land mass).

\section{A special case: divergent anticyclonic forced eddies}

According to the discussion presented earlier, all three terms in Equation 1 have the same sign. Thus, when the forcing is anticylonic (i.e. term 3 is negative), all three terms are negative. Accordingly, $w_{\delta}$ is negative, implying downwelling in the interior of the eddy (Fig. 3b) whenever the factor $(\xi+f)$ is positive. But if $(\xi+f)$ has a negative numerical value, the requirement that term 2 maintain a negative sign means that $w_{\delta}$ must then have a positive value to satisfy the equation. In such a case, upwelling would actually occur in the interior of such a forced anticyclonic eddy, in contrast to the more normal case shown in Figure $3 b$.

The characteristic value of $\zeta$ in a circular eddy is given by $c / r$, where $c$ represents the tangential velocity and $r$ represents the distance to the centre of the eddy (i.e. the radius of curvature of the flow). Thus $c / r$ can be greater than $f$, and consequently $(\zeta+f)$ will be negative, when (1) $r$ is very small (i.e. the eddy has a very small diameter), (2) $c$ is very large (i.e. the eddy is rotating very rapidly), or (3) $f$ is very small (the eddy is located very near the equator). Table 1 presents a selection of eddy sizes below which, for various values of tangential velocities and latitudes, a forced anticyclonic eddy becomes divergent. Clearly, only very near the equator can substantial divergent anticyclonic eddies exist. To exist at higher latitudes, they must be very small, extremely rapidly rotating ones.

Where such eddies may exist, they offer interesting biological situations. For example, by assembling the knowledge of traditional fishermen on several small islands of the Palau group in the equatorial Pacific, Johannes (1981) inferred a complex flow pattern forming downstream of the islands (Fig. 6), which lie in the paths of strong equatorial current
TABLE 1. - Circumferential current speeds $\left(\mathrm{cm} \mathrm{s}^{-1}\right)$ above which a forced anticyclonic eddy will be divergent (upwelling in centre) rather than convergent, as a function of latitude and eddy diameter.

\begin{tabular}{lccccc}
\hline Latitude & $1 \mathrm{~km}$ & $10 \mathrm{~km}$ & $50 \mathrm{~km}$ & $100 \mathrm{~km}$ & $500 \mathrm{~km}$ \\
\hline $90^{\circ}$ & 7.3 & 72.7 & 363.6 & 727.2 & 3636.1 \\
$80^{\circ}$ & 7.2 & 71.6 & 358.1 & 716.2 & 3580.9 \\
$70^{\circ}$ & 6.8 & 68.3 & 341.7 & 683.4 & 3416.8 \\
$60^{\circ}$ & 6.3 & 63.0 & 314.9 & 629.8 & 3149.0 \\
$50^{\circ}$ & 5.6 & 55.7 & 278.5 & 557.1 & 2785.4 \\
$40^{\circ}$ & 4.7 & 46.7 & 233.7 & 467.4 & 2337.2 \\
$30^{\circ}$ & 3.6 & 36.4 & 181.8 & 363.6 & 1818.1 \\
$20^{\circ}$ & 2.5 & 24.9 & 124.4 & 248.7 & 1243.6 \\
$10^{\circ}$ & 1.3 & 12.6 & 63.1 & 126.3 & 631.4 \\
$5^{\circ}$ & 0.6 & 6.3 & 31.7 & 63.4 & 316.9 \\
$4^{\circ}$ & 0.5 & 5.1 & 25.4 & 50.7 & 253.6 \\
$3^{\circ}$ & 0.4 & 3.8 & 19.0 & 38.1 & 190.3 \\
$2^{\circ}$ & 0.3 & 2.5 & 12.7 & 25.4 & 126.9 \\
$1^{\circ}$ & 0.1 & 1.3 & 6.3 & 12.7 & 63.5 \\
$0^{\circ}$ & 0.0 & 0.0 & 0.0 & 0.0 & 0.0 \\
\hline
\end{tabular}

flows. The obstruction of the island creates a sheltered zone of relatively slack flow extending behind the island. Johannes describes a coupled pair of elongated, rapidly-rotating eddies, one cyclonic and one anticyclonic, and shows locations of concentrations of tuna and flying fish oriented to narrow bands of particularly strong current flowing along the outer sides of each of the eddies. The native fishermen habitually launch their boats where these strong flow bands skirt near to the island and are carried to the zones of fish concentration. They later return to the island in the band of return flow between the eddies. Tuna also are said to concentrate near the stagnation zone at the island's upstream side that is produced by the blockage of the incident flow by the island's landmass. (Fig. 6).

One can infer the mechanisms behind the features in Figure 6 using the considerations developed in this section. Momentum of the prevailing flow encountering the island obstruction would create an accumulation of water and a local "high" in the sea surface topography in the stagnation zone. This would tend to accelerate the down-gradient flow skirting either side of the island obstruction, creating the narrow bands of particularly swift flow extending downstream from each lateral edge of the island/reef obstruction. These bands would provide the lateral torques that drive the two counter-rotating elongate eddies behind the island.

The actual island depicted in Johannes's diagram is Tome Island, which is located in the area of the North Equatorial Countercurrent, at about $3^{\circ} \mathrm{N}$ latitude. He reports that speeds of the current prevailing current reach about 2 knots $\left(\sim 100 \mathrm{~cm} \mathrm{~s}^{-2}\right)$. From the 


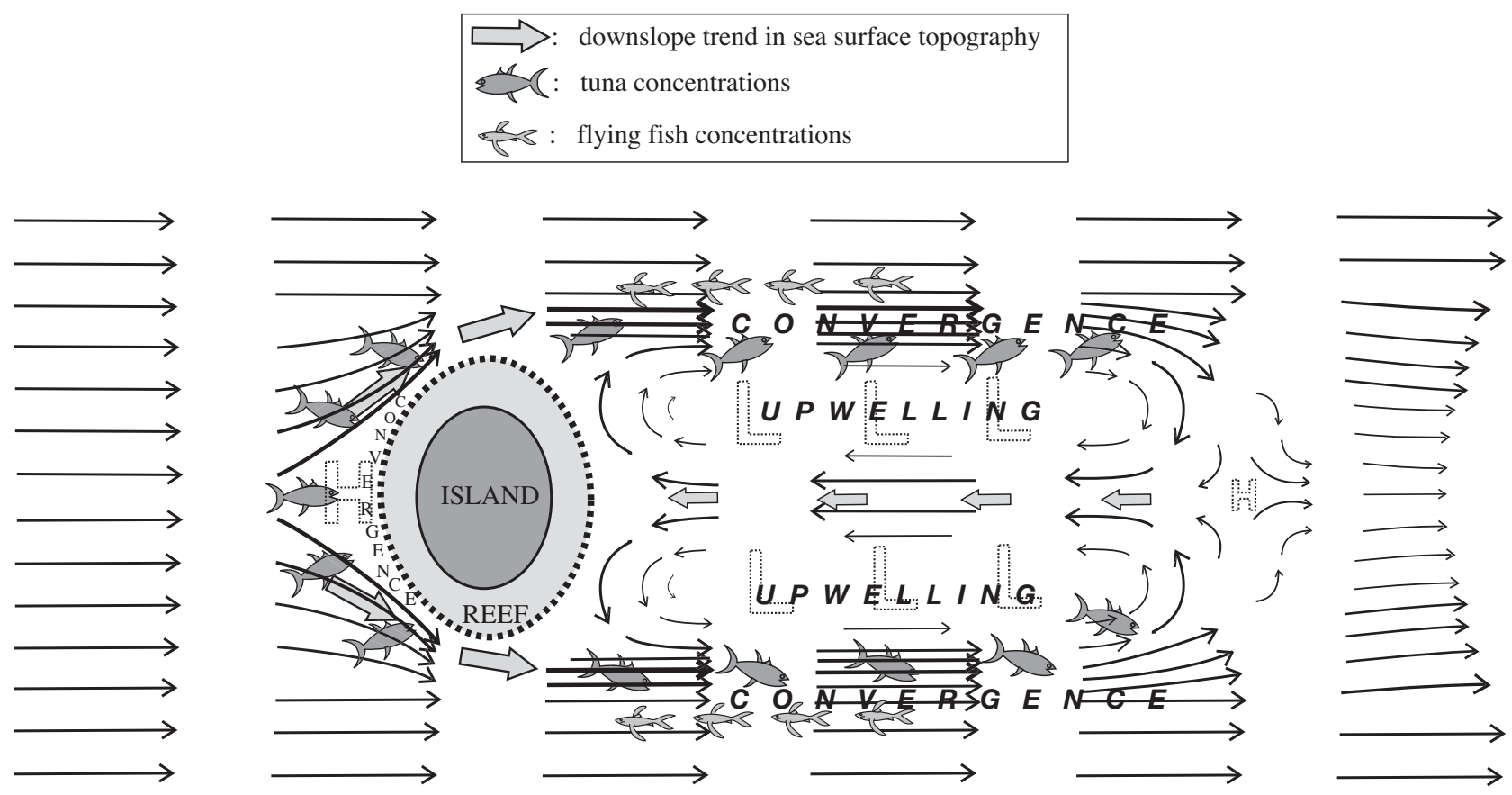

FIG. 6. - Circulation pattern and fishing zones near Tome Island, Palau, as inferred by Johannes (1981) from information gathered in interviews with local artisanal fishermen. Indications of zones of upwelling and flow convergence, as well as features in the sea surface topography accounting for the inferred dynamics, have been added.

size of Tome (less that two $\mathrm{km}$ in diameter), one estimates the eddies depicted to extend $2-3 \mathrm{~km}$ on their longer axes and to be less than one $\mathrm{km}$ on the shorter axes. From Table 1 it is clear that both eddies, the anticyclonic one as well as the cyclonic one, must be strongly divergent and therefore driving strong upwelling in their interiors. There would appear to be little horizontal shear in the return flow between the eddies, as no features suggesting strong convergence or divergence are noted. However, there should be bands of strong convergence at the outer edges of both eddies, on the right sides of the accelerated flow maxima.

All this combines to produce a classic ocean triad (Bakun, 1996; Agostini and Bakun, 2002): (1) upwelling-driven enrichment within the interiors of both eddies, and undoubtedly also some enrichment from upward water movement generated by momentum-driven lifting of the incident prevailing flow upward onto the shallowing sea floor topography at the front of the island/reef obstruction; (2) concentration in the convergence zones located near the strong flow bands of accelerated flow on each side of the elongated eddy pair, and also against the front of the island/reef barrier; and (3) retention of larvae and other planktonic organisms in the local system by the gyral circulation patterns around the eddies, and particularly by the return flow between them. No doubt this type of near-equatorial triad system can offer an excellent nutritional situation for the larvae of reef fishes and invertebrates, and probably also for early life stages of some types of oceanic pelagic fishes, as well as mechanisms to retain larvae within that favourable situation. In addition, the same mechanisms would aid in keeping substantial numbers of potential progeny in the vicinity of suitable habitat for eventual successful recruitment to their adult life styles. Clearly such self-recruitment (Cowen et al., 2000) must be extremely important to maintenance of such small, largely isolated island ecosystems. Moreover, the several concentration zones identified in Figure 6 would act to accumulate high concentrations of food organisms, and also a certain amount of attractive drifting flotsam (see page 107), that might attract oceanic visitors such as flying fish and other planktivores, which in turn attract tuna and other predatory fish (Fig. 6) that may also experience an attractive reaction to the accumulated flotsam. These offer a resource to the local fishers that may far exceed the sustainable production capacity of the local island system itself.

Johannes indicates that the circulation pattern depicted in Figure 6 is not unique to Tome Island 
$\left(3^{\circ} \mathrm{N}\right)$. His interview studies focused on several islands within the small nation of Palau, where he found almost identical accounts from the fishing communities of Sonsorol $\left(5^{\circ} \mathrm{N}\right)$ and Pulo Anna $\left(5^{\circ} \mathrm{N}\right)$. He also mentions an account by Randall (1977) of a similar current pattern forming downstream of Linungan Island $\left(6^{\circ} \mathrm{N}\right)$, which lies in the Basilan Strait off the southern coast of Mindanao in the Philippines.

\section{OPPORTUNITY AND ADVANTAGE}

The discussion in the previous subsection provides a good illustration of the hard reality in marine ecosystems, where "food heaven" tends to directly coincide with "predation hell" (Bakun, 1996). If planktonic food particles suitable for fish larvae can be concentrated in convergent frontal structures, so can planktonic predators (medusas, ctenaphores, predatory larvae of other fishes, etc.) that prey on those larvae. If an innate attraction to drifting objects can position adult fish to feed within, and spawn offspring into, those structures, predatory fishes can use the same attraction to position themselves to prey upon those offspring. Under such circumstances, the key to reproductive success would seem to be to somehow manage to insert larvae into a situation where reasonably good feeding conditions, leading to rapid growth through the most dangerous early life stages, happen to coincide with a low enough density of predators to permit significant survival.

\section{The "predator pit"}

Bakun (in press) offered a simple formalism to encapsulate and demonstrate the gross dynamic effects of these kinds of interactions. The predator pit function (Fig. 7a) features a refuge from predation when prey abundance is very low. But when prey density exceeds a level sufficient to attract predator interest, very destructive predation occurs, with the predators essentially eating all the prey they can locate and capture. However, if the prey abundance reaches a level sufficient to satiate local predators, specific (i.e. per unit prey abundance) predation mortality steadily decreases as prey density increases beyond this satiation level.

If the specific prey production rate is then superimposed on the predator pit function (in the manner shown in Figure $7 b$ ), a critical intersection point appears, below which population abundance will fall (collapse into the pit) and above which abun-
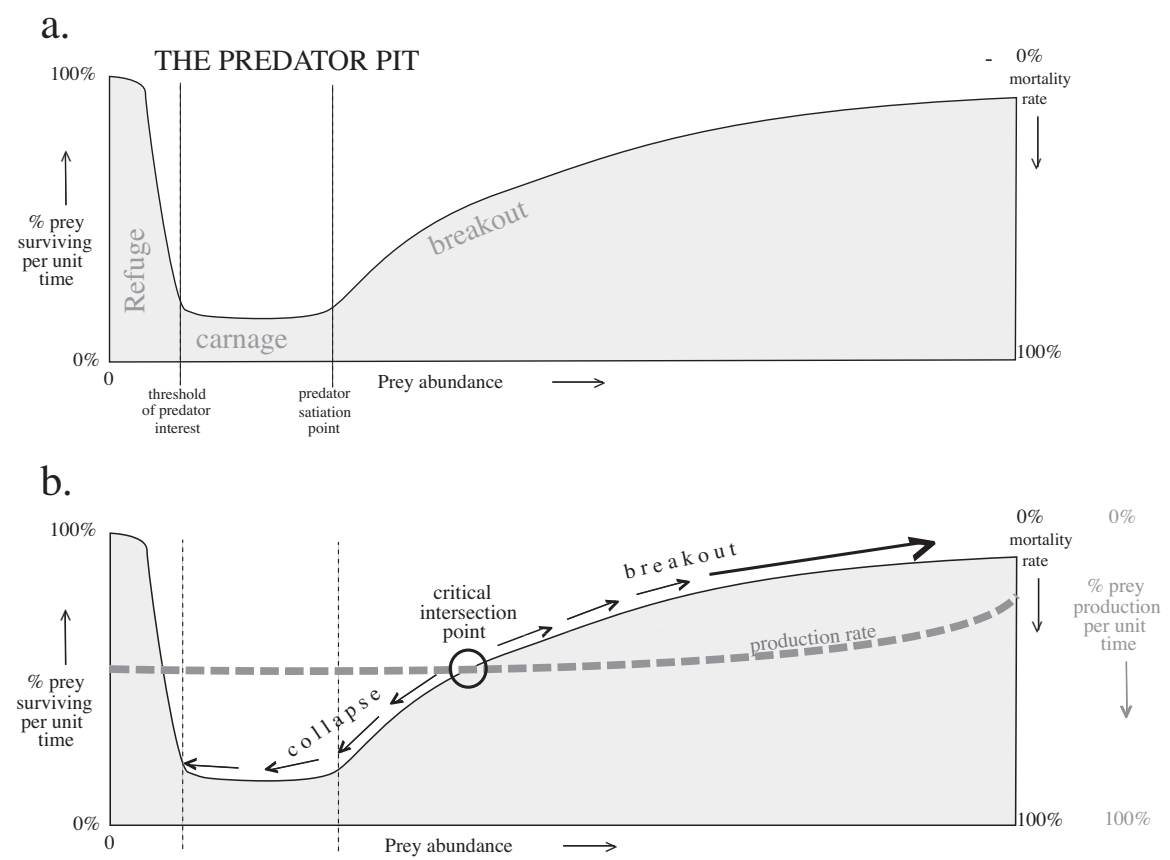

FIG. 7. - (a) Diagram of the predator pit function. Survival rate (plotted on the left ordinate) increases upwards. Mortality rate (plotted on the right ordinate) increases downwards. (b) Production rate curve (biomass produced per unit biomass per unit time - dashed grey curve) of the prey population superimposed on its predator pit function. A critical intersection point (circled), where the two curves intersect, marks the abundance level above which the rate of production exceeds the rate of predation mortality and the population increases (prey population achieves breakout) and below which the rate of predation mortality exceeds the rate of production (prey population collapses into the pit). 
dance will tend to break out dramatically. In the real ocean, the terrain of predator pit topographies is undoubtedly highly variable in time and space, reflecting (a) certain more or less predictable seasonal and geographic aspects upon which (b) a high degree of rather random (unpredictable) short-scale spatial and temporal "noise", as well as (c) longer term climatic "red noise" and multi-year ecosystem trends are superimposed. From the point of view of this predator pit conceptual framework, the feeding and spawning habits of a successful fish population will have been attuned by natural selection to the quasi-predictable features of this continually varying and developing ecosystem landscape. There may also be some ability to track and adaptively respond to multi-year trends in habitat suitability via mechanisms such as "school-fix feedback" (Bakun, 2005a). According to this framework, achieving an episode of very successful reproduction would imply spawning offspring into a situation in which a relatively shallow predator pit may co-exist with feeding opportunities sufficient to support an adequate production rate to allow the critical intersection point in the diagram (Fig. $7 b$ ) to be broached and thereby to produce a "breakout" in survivorship.

\section{Strategies in achieving breakout}

Different fish species appear to use somewhat differing strategies to accomplish this. Serial batch spawners such as sardines and anchovies appear to address the random component of the short-scale temporal and spatial variability through a lottery approach, spawning frequently and repeatedly during an extended spawning season in order to eventually hit a favourable combination of adequate feeding opportunities with a sufficiently shallow local predator pit. In this, sardines appear particularly to favour a shallower predator pit, reproducing relatively well during periods of low system productivity such as El Niño episodes in the eastern Pacific, even though their production rate must suffer. Contrastingly, anchovies tend to reproduce very poorly under such poorly productive conditions, but much better than sardines during highly productive periods. This may offer some explanation for the pattern of out-of-phase alternations in abundance of anchovies and sardines that have characterised many of the marine ecosystems that they share (Bakun and Broad, 2003; Bakun, 2006). It may be that tropical tunas such as yellowfin and skipjack are following a similar serial-batch-spawning lottery approach.

Other fish species take an opposite approach. Rather than spreading their bets widely as do sardines and anchovies, many fishes (such as herring and tropical groupers), assemble, sometimes from long distances, to spawn in very dense spawning aggregations in order to concentrate their spawning within a sufficiently narrow space-time window so that the resulting density of their eggs and larvae may be sufficient to surpass the satiation point for the local predators (i.e. to reach a point far enough to the right in the diagram of Figure 7 where the predator pit has shallowed sufficiently for the intersection with the production rate curve to lie to the left of that point, allowing a significant breakout in survivorship).

\section{Illustration: North Pacific albacore tuna}

The less tropical of the large tunas, the albacore and the bluefin tunas, travel particularly long distances to spawn in rather poorly productive regions of the ocean, in spite of the fact that their early stages are among the most voraciously predatory and fastest growing of all fishes. For example, the Pacific albacore migrates many thousands of kilometres from rich pre-adult feeding grounds off the upwelling zones of the California Current and in the Kuroshio-Oyashio confluence zone to spawn in the tropical zone of the west-central North Pacific (Fig. 8 ), which is a quite poorly productive area, at least as far as large-scale average primary productivity (FAO, 1972) is concerned.

Bakun (1996) pointed out that the albacore have adapted to place their larvae where the core of maximum velocity of the northeast trade winds veers particularly close to the equator (Fig. 8). Such a wind maximum produces bands of cyclonic and anticyclonic wind stress curl on either side, which according to Equation 1 and Equation 2 (term 3b) would be characterised by surface layer convergence and downwelling in the zone on the right (northern) side and divergence and upwelling on the left (southern side). Note that as the equator is approached the value of $f$, which on large scales controls the magnitude of the factor $(\xi+f)$ in term 2 of Equation 1 (discussed on page 115), drops precipitously. Maintaining the balance between terms 2 and 3 of Equation 1 thus implies dramatic increases in vertical motions (and associated convergence or 


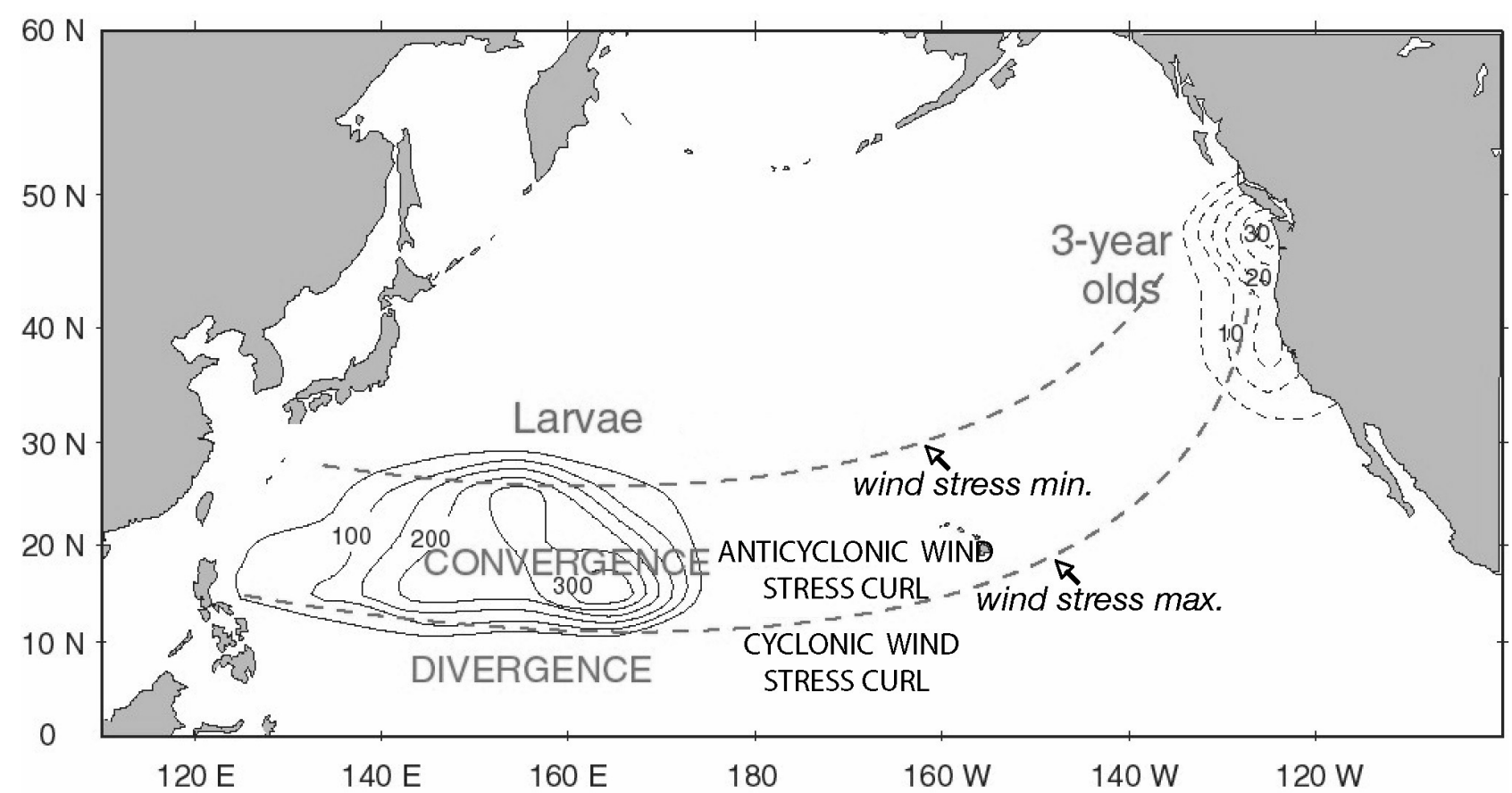

FIG. 8. - Distribution of albacore larvae (solid contours) and of 3-year-old fish caught in the California Current (dashed contours). Heavy dashed lines indicate the average position of maximum intensity of westward-directed wind stress, and the corresponding north side minimum in westward-directed wind stress. There is Ekman divergence (cyclonic wind stress curl) to the south of the wind maximum, and Ekman convergence (anticyclonic wind stress curl) to the north. Larvae are distributed in the convergent zone of anticyclonic wind stress curl, at the point where the stress maximum veers nearest to the equator. [Units: number of larvae per million cubic meters (from Nishikawa et al., 1985); distribution of catch locations of 221,221 albacore sampled in the North Pacific (R.H. Parrish, personal communication).] After Bakun (1996).

divergence) produced in response to a given intensity of torque (term 3 ) exerted by wind stress curl acting on the sea surface. Thus, at very low latitudes, even a quite low wind intensity, producing minimal turbulence input that could inhibit primary production or cause feeding difficulties to fish larvae and other small organisms, can produce strong upwelling and resulting enrichment on the southern side of the wind stress maximum. The products of this enrichment can then be carried in the northward-directed Ekman transport field (in the northern hemisphere, wind-driven surface Ekman transport is directed $90^{\circ}$ to the right of the wind), which is likewise very strong due to the minimal magnitude of $f$, to the zone of strong convergence on the northern side of the line of maximum stress. As discussed repeatedly above, the convergent area represents a zone of concentration of small organisms resulting from the trophic succession originating in the enrichment zone. This is where the albacore deposit their voraciously feeding larvae (Fig. 8).

The respective zones of intense divergence and upwelling, and of intense convergence and downwelling, overlie and contribute to production of corresponding zones of doming and of downwarping of the subsurface density structure. The position of the maximum in wind stress accordingly marks the southern boundary of a zone of sharp dip of the density structure, which in this case corresponds to (and acts to reinforce) the high velocity core of the North Equatorial Current. Thus, the lateral frictional torques are in the correct sense for producing forced cyclonic (upwelling) mesoscale eddies on the right (southern) side, the products of which can be carried in the northward Ekman transport to the anticyclonic (downwelling) eddies on the left (northern) side of that core, producing a congruent linked enrichment and concentration configuration to that produced by the wind. These two nested, mutually supportive sets of coupled processes of enrichment and concentration evidently act in concert to create favourable circumstances for larval feeding and growth.

The area would appear also to be particularly favourable with regard to the predator pits facing these larvae in that the intense North Equatorial Current flowing through this zone presents a major problem of population maintenance to fish and other organisms of a size to prey upon, or compete with, tuna larvae. Moreover, it enters the zone from an area where the enrichment-convergence couple is much less intense (the wind stress maximum producing the coupled bands of divergence and convergence typi- 
cally being positioned well to the north; Figure 8), with the result that advective input of such competitors produced upstream would tend to be greatly suppressed. In contrast, the large tunas enjoy the advantage that, by growing to large size and being particularly efficient long-distance swimmers, they can close their own life cycles (i.e. maintain population in such a rapid, dispersive, flow system) by shear swimming power of the adults, which can thus traverse ocean areas that competing species are not able to negotiate, in order to deposit their early stages at the most favourable time and location with respect to both production rate (nutrition) and depth of the local larval predator pits, thereby maximising the probability of achieving a breakout (Fig. 7b).

\section{Illustration: North Atlantic bluefin tuna}

In the north Atlantic Ocean, bluefin tuna, the largest, most valuable, and probably most threatened, species of tuna, are known to spawn only in two areas: (1) in the Loop Current of the Gulf of Mexico and (2) inside the Mediterranean Sea. The Loop Current is a very swift current that carries oligotrophic surface waters from the tropical central Atlantic Ocean into the Gulf of Mexico, making an anticyclonic loop toward the Straits of Florida, where it exits the Gulf to feed the Gulf Stream. Bluefin tuna in the Gulf of Mexico are observed to concentrate in the vicinity of surface fronts associated with the Loop Current (Maul et al., 1984; Richards et al., 1989). The tendency for cyclonic frontal eddy formation on the coastward (left) side of such a current (Fig. 4) provides a local enrichment mechanism. This is superimposed on the general anticyclonic flow pattern of the Loop Current, which presents a larger scale pattern of convergence, favouring the formation of convergent frontal structures, a tendency further abetted by the strong cross-flow gradient in water density characterising such an intense ocean current. Moreover, the eddy action in the vicinity of the front represents frictional retardation of the current velocity, which reduces the Coriolis force acting to prevent the heavier Gulf surface water from encroaching into the frontal zone. This allows these higher-density waters to move toward and mix with Loop Current surface water in the frontal zone, enhancing production of the mixed water mass having a high enough density to undermine (sink beneath) the Loop Current surface water. This creates the descending motion in the frontal zone and the associated concentration mechanism displayed in Figure 1. Furthermore, the situation presents similarities to the North Equatorial Current situation in that here an even more intense unidirectional flow system presents population maintenance problems to potential predators or competitors to tuna larvae. In contrast, adult bluefin tuna are very well equipped, by their size and swimming ability, to solve these problems. These capabilities make it possible for the bluefin to place larvae within a particularly shallow predator pit situation, at a point in time and space where a trophic succession might yield a sufficiency of appropriate larval food organisms.

The other spawning area, the Mediterranean Sea, is well known to be an oligatrophic sea. There do exist fairly intense coastal upwelling zones inside the Mediterranean (Bakun and Agostini, 2001), but the bluefin do not go to those areas to spawn. Rather they position their spawning activity in areas of particularly poor primary productivity near the Balearic Islands, near island groups off Sicily, etc. However, a characteristic of these spawning areas appears to be the interaction of fairly strong currents with the obstructions represented by the islands, to generate strong lateral frictional torques that can support the formation of mesoscale eddies and convergent fronts (García et al., in preparation). Most of the larvae are found in the anticyclonic eddy structures where larval food organisms would tend to be concentrated in the convergent flow patterns (ibid.). Similarly to the preceding two examples, the size and swimming ability of the large tunas may allow them to cross the less suitable areas of the Mediterranean to insert larvae into particularly favourable situations, from which potential predators or competitors with much weaker migrational capacities may be precluded, maximising the probability of achieving a survival breakout (Fig. 7b).

\section{CONCLUDING REMARKS: IMPLICATIONS FOR PROCESS-ORIENTED RESEARCH}

Conventionally, in situ research investigations into the factors that control reproductive success in fishery resource populations have focused their efforts on sampling the temporal-spatial "average" scale that may characterize a major portion of the reproductive habitat and seasonal peak spawning period. In such cases, limitations in available resources generally dictate a fairly gross resolution 
in the sampling scheme. Often the temporal component of variation is considered to be stationary over the period required to collect a complete spatial pattern of samples. Such an approach tends to preclude addressing processes evolving on the sub-seasonal temporal scale and on the "meso" spatial scale, while the arguments presented in this paper suggest that these sub-seasonal meso-scale environmental processes may often be the crucial ones regulating population-scale reproductive success, and by implication, the population dynamics of the resource as a whole. Rather, the investigations are forced to focus on static associations with "average-scale" properties (temperature, dissolved oxygen level, water column stability, etc.) rather than on processes. These associations have served mainly to identify rather broad environmental envelopes within which spawning may ordinarily occur. However, they have not yielded breakthroughs in insight into the operation of the mechanisms underlying radical variability in reproductive success, and much less into those fostering "regime shifts" (Bakun, 2005b) that may produce catastrophic losses of traditionally dominant positions of favoured resource species in a regional marine ecosystem structure.

There seems to be no good reason why, with the research tools now available, it should not be possible to simply change the current fashion in the design of process-oriented in situ fishery-ecological research activities to one of directly addressing these mesoscale, higher frequency phenomena. Once a group develops an idea of what they may be looking for, real-time satellite imagery could allow the initiation and evolution of frontal and eddy structures to be monitored. The theory represented by Eqs. 1 and 2 (and suggested in the various figures presented in this paper) along with well-posed hypotheses as to the effect on the relevant biological processes, could allow available sampling resources to be allocated in a flexible, specifically-directed manner to directly address and explicate particular causal mechanisms. Perhaps such a change in fashion could permit fisheries science to at last move forward from the state in which, in the opinion of many, it has been largely frozen for a number of decades, and to begin to accumulate the mechanistic understanding required to move it from its traditional character as a sort of operational art to the status of a true prognostic science (i.e. capable of specifying in a soundly-based, comprehensive manner the nature and range of probable outcomes of influences imposed and actions taken).

\section{ACKNOWLEDGEMENTS}

This paper is a contribution of the Adverse EcoFeedbacks Project of the Pew Institute of Ocean Science, which is funded by the Pew Charitable Trusts.

\section{REFERENCES}

Bakun, A. - 1996. Patterns in the Ocean: Ocean Processes and Marine Population Dynamics. University of California Sea Grant, San Diego, California, USA, in cooperation with Centro de Investigaciones Biológicas de Noroeste, La Paz, Baja California Sur, Mexico.

Bakun, A. - 2005a. Seeking an expanded suite of management tools: implications of rapidly-evolving adaptive response mechanisms (e.g., "school-mix feedback"). Bull. Mar. Sci., 76: 463-483.

Bakun, A. - 2005b. Regime Shifts. In: A.R. Robinson, and K. Brink (eds.), The Sea, Volume 13, pp. 971-1026. Harvard Univ. Press, Cambridge, Mass.

Bakun, A. - 2006. Wasp-waist populations and marine ecosystem dynamics: Navigating the predator pit topographies. Prog. Oceanogr., 68: 271-288.

Bakun, A. and V.N. Agostini. - 2001. Seasonal patterns of winddriven upwelling/downwelling in the Mediterranean Sea. Sci. Mar., 65: 243-257.

Bakun, A. and K. Broad. - 2003. Environmental loopholes and fish population dynamics: comparative pattern recognition with particular focus on El Niño effects in the Pacific. Fish. Oceanogr., 12: $458-473$.

Bakun, A. and C.S. Nelson. - 1991. Wind stress curl in subtropical eastern boundary current regions. J. Phys. Oceanogr., 21: 1815-1834.

Ciechomski, J.D. de and R.P. Sánchez. - 1986. Problematica del estudio de huevos y larvas de anchoíta (Engraulis anchoita) en relacion con la evolucion de sus efectivos pesqueros. l Resena de viente años de investigacion. Publ. Com. Tec. Mix. Fr. Marl., 1(1): 93-109.

Cowen, R.K., K.M.M. Lwiza, S. Sponaugle, C.B. Paris and D.B. Olson. - 2000. Connectivity of marine populations: open or closed? Science, 297: 2019-2025.

FAO. -1972. Atlas of the Living Resources of the Sea. Food and Agriculture Organization of the United Nations, Rome.

Glorioso, P.D., A.R. Piola, and R.R. Leben. - 2005. Mesoscale eddies on the Subarctic Front - Southwest Atlantic. Sci. Mar., 69(Suppl. 2): 7-15.

García, A., A. Bakun and D. Margulies. - 2006. Report of the CLIOTOP Workshop of Working Group 1 on Early Life History of Top Predators. ICCAT, SCRS/2006/123.

Hess, S.L. - 1959. Introduction to Theoretical Meteorology. Holt-Dryden, New York.

Johannes, R.E. - 1981. Words of the Lagoon. Univ. California Press, Berkeley.

Legendre, L. and S. Demers. - 1984. Towards dynamic biological oceanography and limnology. Can. J. Fish. Aquat. Sci., 41: 2-19.

Matsuura, Y., J.C. Amaral, G. Sato and S.T.J. Tamassia. - 1985. Ocorrência de peixes pelágicos e a estrutura oceanográfica da região entre o Cabo de São Tome $(\mathrm{RJ})$ e Cananeia (SP), em JanFev/1979. Ser. Doc. Tec., PDP/SUDEPE, Brasilia, 33: 3-70.

Maul, G.A., F. Williams, M. Roffer and F.M. Sousa. - 1984. Remotely sensed oceanographic pattern and variability of bluefin tuna catch in the Gulf of Mexico. Oceanolog. Acta, 7: 469-479.

Nishikawa, Y., M. Honma, S. Ueyanagi and S. Kikawa. - 1985. Average distribution of larvae of oceanic species of Scombrid fishes, 1956-1981. Far Seas Fish. Res. Lab., S Series, 12: 1-99.

Olson, D.B. - 1980. The Physical Oceanography of Two Rings Observed by the Cyclonic Ring Experiment. Part II: Dynamics. J. Phys. Oceanogr., 10: 514-528.

Olson, D.B. - 1991. Rings in the Ocean. Ann. Rev. Earth Planet. Sci., 19: 283-311 
Parrish, R.H. A. Bakun, D.M. Husby and C.S. Nelson - 1983. Comparative climatology of selected environmental processes in relation to eastern boundary current pelagic fish reproduction. pp. 731-778. In: G.D. Sharp and J. Csirke (eds.), Proceedings of the Expert Consultation to Examine Changes in Abundance and Species Composition of Neritic Fish Resources. FAO Fish. Rep., 291 (2,3). 1224 pp.

Pikitch, E.K., C. Santora, E.A. Babcock, A. Bakun, R. Bonfil, D.O. Conover, P. Dayton, P. Doukakis, D. Fluharty, B. Heneman, E.D. Houde, J. Link, P.A. Livingston, M. Mangel, M.K. McAllister, J. Pope and K.J. Sainsbury. - 2004. EcosystemBased Fishery Management. Science, 305: 346-347.

Richards, W.J., T. Lemming, M.F. McGowan, J.T. Lamkin and S. Kelley-Fraga. - 1989. Distribution of fish larvae in relation to hydrographic features of the Loop Current boundary in the Gulf of Mexico. Rapp P.-v. Réun. Cons. int. Explor. Mer, 191: 169-176.

Randall, R.A. - 1977. Change and variation in Samal fishing: making plans to "make a living" in the Southern Philippines. Ph.D. thesis, Univ. California, Riverside.

Seki, M.P., R. Lumpkin and P. Flament. - 2002. Hawaii cyclonic eddies and blue marlin catches: The case study of the 1995 Hawaiian International Billfish Tournament. J. Oceanogr., 58 739-745.

Seki, M.P., J.J. Polovina, R.E. Brainard, R.R. Bidigare, C.L. Leonard and D.G. Foley. - 2001. Biological enhancement at cyclonic eddies tracked with GOES thermal imagery in Hawaiian waters. Geophys. Res. Lett., 28: 1583-1586.

Smith, R.L. - 1968. Upwelling. Oceanogr. Mar. Biol. Ann. Rev., 6: $11-46$

Spiegel, M.R. - 1959. Theory and Problems in Vector Analysis. Schaum's Outline Series, Schaum Pub. Co., New York.

You, Y - 2003. Implications of cabbeling on the formation and transformation mechanism of North Pacific Intermediate Water. J. Geophys. Res., 108 (C5), 3134, doi:10.1029/ 2001JC001285.

Yun, J.-Y., and L.D. Talley. - 2003: Cabbeling and the density of the North Pacific Intermediate Water quantified by an inverse method. J. Geophys. Res., 108 (C4), 10.1029/2002JC001482.

Received November 1, 2005. Accepted March 3, 2006.

Published online September 26, 2006. 